\title{
Diagnosing and treating Krukenberg tumor: a gynecologist's dilemma
}

\author{
Danu Chandradas ${ }^{1 *}$, Betsy Thomas $^{1}$, Abhilash Jayachandran ${ }^{2}$
}

\author{
${ }^{1}$ Department of Obstetrics \& Gynaecology, Amala Institute of Medical Sciences, Amala Nagar, Thrissur, Kerala, India \\ ${ }^{2}$ Department of General Surgery, Vinayaka Mission Medical College, Karaikal, Pondicherry, India
}

Received: 25 September 2015

Accepted: 01 November 2015

\section{*Correspondence:}

Dr. Danu Chandradas,

E-mail: danu_chand@yahoo.co.in

Copyright: ( $)$ the author(s), publisher and licensee Medip Academy. This is an open-access article distributed under the terms of the Creative Commons Attribution Non-Commercial License, which permits unrestricted non-commercial use, distribution, and reproduction in any medium, provided the original work is properly cited.

\begin{abstract}
Krukenberg tumor is a rare tumor of ovary. It is a metastatic ovarian tumor usually from a primary in gastrointestinal tract. The lesions are usually not discovered until primary disease is advanced and therefore most patients die within a year. In some cases primary is never found and their prognosis worsens. We are reporting a case on which right ovariotomy was done for a complex right ovarian mass from another hospital. Even after surgery her symptoms persisted and on further evaluation, she was found to have primary gastric carcinoma with carcinoma of recto sigmoid and left Krukenberg tumor. Here the diagnosis of a metastatic disease was missed during the initial evaluation. 80\% of these tumors are bilateral and usually both ovaries are affected at the same time. But in this case, left ovary was normal which later increased in size within just 2 weeks. No optimal treatment strategy is clearly mentioned in literature. Whether to give her a palliative care or a definitive cytoreductive surgery was debated. Recent literature says that if we can render the patient free of gross residual disease, we should do a primary debulking surgery rather than palliative care. Many studies have shown that aggressive debulking of macroscopic disease improves the survival rate.
\end{abstract}

Keywords: Krukenberg tumor, Primary debulking, metastatic ovarian tumor, CA-125, CEA, gastrointestinal malignancy

\section{INTRODUCTION}

Krukenberg tumor is named after Friedrich Ernst Krukenberg who described five cases of Krukenberg tumors in 1896 while working as a student in a laboratory in Germany. ${ }^{1}$ Krukenberg tumor accounts for only $2 \%$ of ovarian cancers. ${ }^{1}$ Histologically, it is characterized by Signet ring cells. ${ }^{1}$ The lesions are usually not discovered until primary disease is advanced and therefore most patients die within a year. The presence of ovarian metastasis in gastrointestinal malignancy worsens the prognosis.

The present case highlights the possibility of missing the diagnosis of a metastatic disease and subjecting the patient to a surgery and also the dilemma of a surgeon in deciding the treatment for such a disease. The current standard treatment for patients with metastatic gastric cancer is systemic chemotherapy. Recently, many studies have shown that primary debulking surgery improves overall survival.

\section{CASE REPORT}

A 43year old P4L4 with regular cycles had complaints of abdominal distension, dysuria and pain during defecation. She was evaluated at another hospital and was diagnosed to have a right ovarian complex mass for which she underwent Laparoscopic right ovariotomy. Her CA-125 was 9.23. Intra-op there was no extra-ovarian disease. Opposite ovary was normal. Histopathology report- Sex cord stromal tumor-unclassified. Few Signet-ring cells were seen.

Just after 2 weeks of surgery, she came to our OPD with similar complaints. She gives past history of chronic 
gastritis under medical treatment. OGD-scopy 4 months back showed only evidence of chronic gastritis. On pervaginal examination a left adnexal firm mass of about $4 \times 4 \mathrm{~cm}$ in size was felt.

Ultrasonography showed heterogenous solid left adnexal mass about $6.8 \times 4.6 \times 4.3 \mathrm{~cm}$ - suggestive of Left ovarian tumor malignant. There was diffuse wall thickening and luminal narrowing of lower sigmoid colon.

CT scan showed irregular wall thickening of body of stomach- possibility of Carcinoma of stomach to be considered. Possibility of neoplastic thickening of Sigmoid colon and a heterogenous enhancing multicystic lesion of left adnexa in close relation to narrowed sigmoid colon with loss of fat plane with uterus notedsuggestive of Krukenberg tumor.

OGD scopy and Biopsy- Mucosal infiltration of fundus and body of stomach- suggestive of linitus plasticus. Flexible Sigmoidoscopy - Stricturing lesion with mucosal infiltration at recto sigmoid. CEA was 1.9 and CA-125 was 41 . Metastasis to other parts was ruled out by Whole body PET-CT.

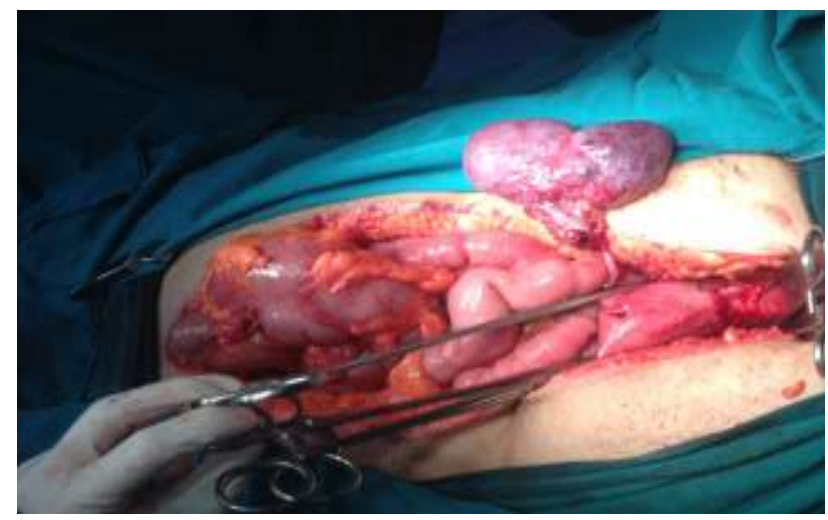

Figure 1: Intra-op picture showing enlarged left ovary. Krukenberg tumor has characteristic tan-white bosselated appearance with preservation of the contour and free of adhesions.

After extensive investigations she was diagnosed to have Primary Gastric malignancy with Carcinoma of Recto sigmoid and Krukenberg tumor.

Further treatment was confusing. Literature says that primary debulking can be done for a metastatic disease like Krukenberg. Since the patient was young, symptomatic and did not have metastasis to any other organs and had good performance status for surgery, we proceeded with debulking surgery (Total gastrectomy + Esophago-jejunostomy + Jejuno-jejunostomy + anterior resection + Hysterectomy + Left salpingo-ovariotomy. Intra-op there was thickening of stomach wall with serosal involvement. No other visceral infiltration noted. Features of colonic obstruction and solid mass of left ovary were seen. Histopathology report- Poorly differentiated Adenocarcinoma of Stomach reaching serosal surface, margins free. Metastatic deposits in recto sigmoid growth. Lymph nodes showed only reactive changes. Left ovary showed Krukenberg deposits.

With the diagnosis of Stage IV disease, she was planned to have 8 cycles of chemotherapy. On regular follow up with USG and MRI, she did not show any evidence of recurrence. She was symptomatically better for 6 months but later developed Grade 3 neutropenia and renal failure due to chemotherapy and succumbed.

\section{DICUSSION}

Krukenberg tumor presents with non-specific GI symptoms. A gynaecologists' mind should be open to the possibility of malignancy outside genital tract also. Prognosis worsens when primary tumor is identified after metastasis to ovary. Prognosis of Krukenberg tumor is extremely poor compared to primary ovarian cancer. Usually patients with ovarian mass, either primary or metastasis, presents with abdominal distension and vague gastrointestinal symptoms like dyspepsia, occasional abdominal pain and difficulty in bowel movements. All these vague symptoms should not be overlooked as simple gastritis or as an associated feature of a benign ovarian neoplasm. Patients especially with history of chronic gastritis should be properly evaluated with CEA, OGD-scopy and if required colonoscopy when patient complaints of altered bowel habits or pain during defecation or bleeding per-rectum. By meticulous evaluation of the patient, missing out the diagnosis of a metastatic disease can be overcome and proper treatment can be given to the patient.

The prognosis related to timing of definitive diagnosis of Krukenberg tumor; whether before, after or at the same time as diagnosis of primary tumor, the role of prophylactic oophorectomy in patients with gastrointestinal malignancies and role of primary debulking and definitive treatment modality are still debated.

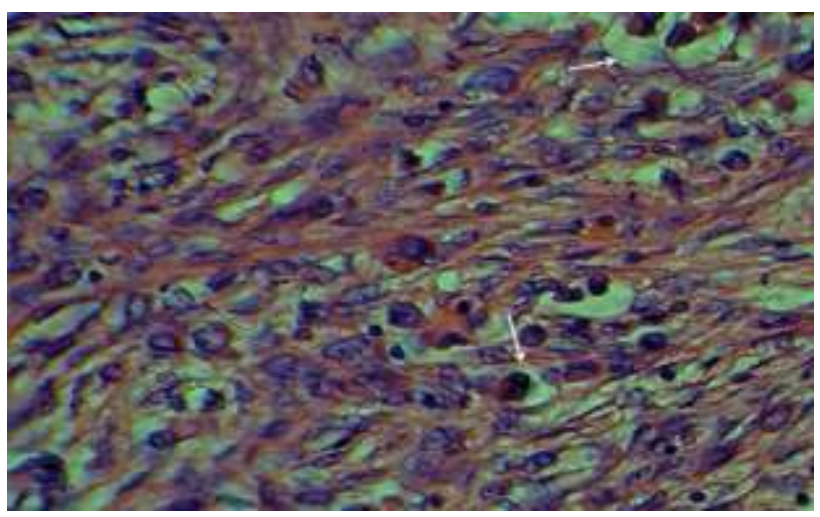

Figure 2: Microscopic picture showing Signet-ring cells (cytoplasm is filled with mucin and nucleus is pushed eccentrically). 
In the past, a stage 4 disease like Krukenberg tumor was treated with systemic chemotherapy alone. Then came the role of palliative surgical resection of ovarian mass to relieve the pressure symptoms. Many surgeons consider that the current standard treatment for patients with metastatic gastric cancer is systemic chemotherapy. Recently, many studies are going on to know whether a complete cytoreductive surgery which includes removal of the primary as well as the secondary tumor can improve quality of life and survival rate. For Krukenberg tumors, it is not known whether metastasectomy is associated with additional benefits. ${ }^{2-7}$ Bakalakos et al have reported that, in patients with metastatic carcinomas, aggressive surgical therapy may be less beneficial. $^{8}$ Meanwhile, several other studies have observed the significance of resection of ovarian metastasis. Jiang et al and Cheong et al reported that ovarian metastasectomy significantly lengthens overall survival in patients with primary gastric, colorectal or breast cancer. ${ }^{6,7}$ A study conducted by Li-Chun Lu et $\mathrm{al}^{2}$ and Fujiwara et al also concluded that metastasectomy benefits the patient. ${ }^{8}$ Dora, Wing, Moon et al are of the opinion that although recurrence after resection of Krukenberg tumor is common, bilateral salpingoovariotomy should be considered and a more aggressive approach such as debulking surgery is recommended to improve the outcome of the patients. ${ }^{9}$

Now, cytoreductive surgery and Hyperthermic Intraperitoneal Chemotherapy (HIPEC) has become a potentially curative treatment for intra-abdominal metastasis from colorectal malignancies. ${ }^{10}$ In patients with gastrointestinal malignancy, some surgeons even recommend prophylactic oophorectomy during cytoreduction for peritoneal carcinomatosis owing to high risk of ovarian metastasis. Controversies still exist about treatment of Krukenberg tumor. More prospective studies are needed to reach a common conclusion on treatment modality. Due to lack of proper studies, these patients should not be denied the optimum treatment for their disease.

Funding: No funding sources Conflict of interest: None declared Ethical approval: Not required

\section{REFERENCES}

1. Doğanay M, Topçu HO, Kokanal MK, Güzel Aİ, Oskovi A, Akbay S. Krukenberg carcinoma metastasized from stomach resembling mucinous cystadenocarcinoma of the ovary. Journal of experimental therapeutics \& oncology. 2015;11(1):23-6.

2. Lu LC, Shao YY, Hsu CH, HSU C, Cheng WF, Lin $\mathrm{Y}$, et al. Metastasectomy of Krukenberg tumors may be associated with survival benefits in patients with metastatic gastric cancer. Anticancer research. 2012;32(8):3397-401.

3. Kim HK, Heo DS, Bang YJ, Kim NK. Prognostic factors of Krukenberg's tumor. Gynecol Oncol. 2001;82:105-9.

4. Ayhan A, Guvenal T, Salman MC, Ozyuncu O, Sakinci M, Basaran M. The role of cytoreductive surgery in nongenital cancers metastatic to the ovaries. Gynecol Oncol. 2005;98:235-41.

5. Kim WY, Kim TJ, Kim SE, Lee JW, Lee JH, Kim BG. The role of cytoreductive surgery for nongenital tract metastatic tumors to the ovaries. Eur $\mathbf{J}$ Obstet Gynecol Reprod Biol. 2010;149:97-101.

6. Jiang R, Tang J, Cheng X, Zang RY. Surgical treatment for patients with different origins of Krukenberg tumors: Outcomes and prognostic factors. Eur J Surg Oncol. 2009;35:92-7.

7. Cheong JH, Hyung WJ, Chen J, Kim J, Choi SH, Noh SH. Survival benefit of metastasectomy for Krukenberg tumors from gastric cancer. Gynecol Oncol. 2004;94:477-82.

8. Fujiwara A, Noura S, Ohue M, Shingai T, Yamada, T, Miyashiro I, et al. Significance of the resection of ovarian metastasis from colorectal cancers. J Surg Oncol. 2010;102:582-7.

9. Tai DKC, Li WH, Cheung MT. Krukenberg tumours of colorectal origin: Experience of a tertiary referral centre and review of the literature. Surgical Practice. 2012;16:46-52.

10. Evers DJ, Verwaal VJ. Indication for oophorectomy during cytoreduction for intraperitoneal metastatic spread of colorectal or appendiceal origin. Br J Surg. 2011;98:287-92.

Cite this article as: Chandradas D, Thomas B, Jayachandran A. Diagnosing and treating Krukenberg tumor: a gynecologist's dilemma. Int J Reprod Contracept Obstet Gynecol 2015;4:2069-71. 